\title{
How Mental Health and Well Being was influenced by Psycho Buddies - an innovative and experiential teaching learning method
}

\author{
Sundari $\mathrm{KP}^{1}$, Vrushali Pendse ${ }^{2}$, Bhagyashree Sawant ${ }^{3}$ \\ ${ }^{1}$ Vice Principal and Head, \\ ${ }^{2}$ Assistant Professor, \\ Department of Psychology, M.D. College, Parel, Mumbai \\ ${ }^{3}$ Post Graduate Student (M.Sc. Psychology), Surana College, Bangalore \\ E-mail - sundarigandhi@yahoo.com
}

\begin{abstract}
Background: Mental health and individual well-being plays an important role in the overall development for a person irrespective of the socio-economic background, age, gender, and ethnicity. These life resources if restricted or underdeveloped tend to create emotional disturbances in a being which affects life in all areas. It is of increasing importance to teach and imbibe these life values in students of all age-group for a holistic, congruent and integrated developed being. The authors of this study aim to understand how innovative teaching methods enhance the mental health and well-being of the undergraduate students. It aims to see how the teaching-learning methods are instrumental in building up overall efficiency, interpersonal relations, sociability, life satisfaction and mental health in the students.

Methodology: A sample of 136 students with and without exposure to the teaching innovations each would be evaluated on the well-being scale. The authors believe that Psycho Buddies give students an excellent opportunity to develop essential life skills like leadership, team management, goal oriented action plans, focused efforts for career growth and a constructive pattern of thought process and adaptive emotional expression. The activities sensitize the students toward individual well-being and social responsibilities viz. life skill development, essential nutritional diet, community outreach for awareness and execution ability for health, financial and environment concerns. The Psychological Well-being scale was administered on the total sample of 136 .

Results:
\end{abstract}

Key words: individual well-being, student mental health, life skills, constructive thought patterns, adaptive emotion patterns, Psycho buddies, interpersonal relations, sociability, life satisfaction, efficiency.

(Paper received $-23^{\text {rd }}$ October 2016, Peer review completed $-6^{\text {th }}$ December 2016, Accepted $-15^{\text {th }}$ December 2016)

\section{INTRODUCTION}

Psychological well-being resides within the experience of an individual [1]. It is a strong sense of selfefficacy that enhances people's wellbeing in many ways. It has been found that high level of self-efficacy contributes to high levels of engagements and life satisfaction. Positive role models, accurate reading of physical and emotional feelings, and positive feedback by educators all contribute to well- being of the student. 


\section{Mental Health}

Student mental health would be defined as the condition with regard to a student's psychological and emotional and social well-being. It has a significant impact on how a student thinks feels and acts. It is a strong determinant for decision making, problem solving skills of the student. The signs of positive mental health include - realizing the student's full potential, coping with daily stressors, productive work strategies, and contributing meaningfully to the community [2].

\section{Life skills}

Life skills education is designed to facilitate the practice and reinforcement of psychosocial skills in a culturally and developmentally appropriate way; it contributes to the promotion of personal and social development, the prevention of health and social problems, and the protection of human rights [3]. The following descriptors too were used to refer psychosocial life skills, dealing with conflict that cannot be resolved, dealing with authority, solving problems, making and keeping friends/relationships, cooperation, self-awareness, creative thinking, decision-making, critical thinking, dealing with stress, negotiation, clarification of values, resisting pressure, coping with disappointment, planning ahead, empathy, dealing with emotions, assertiveness, active listening, respect, tolerance, trust, sharing, sympathy, compassion, sociability, self-esteem.

\section{Constructive thought patterns}

The way an adolescent thinks is determined by his/her past experiences. It reflects the planning strategies used by the adolescent for life goals like career decisions, relationship management; and also for daily and functional needs like planning and implementing study pattern, interacting with authority figures, judging the availability and strength of personal metal resources to deal with difficulties in academics, relations with peers, and so on [4].

\section{Adaptive emotion patterns}

Emotional development is the emergence of a child's experience, expression, understanding, and regulation of emotions from birth through late adolescence. It also comprises how growth and changes in these processes concerning emotions occur. Emotional development does not occur in isolation; neural, cognitive, and behavioral development interact with emotional development and social and cultural influences, and context also play a role [5].

\section{Psycho Buddies}

In the current study, the authors wish to emphasize on the innovation introduced in the teaching method and how experiential confrontation or self-disclosure can help students learn better. The authors identified the major concerns faced by the students for low performance in academics and fragmented functioning at behavioral and emotional level in daily life. Keeping in mind the factors beyond control (improving their lifestyle, SES, home environment) which could be majorly influencing their academic and personal growth, the authors devised a strategy to fill in those gaps and fragments during the college hours. The Psycho Buddies project was invented with rigorous planning. The activities of Psycho Buddies were designed keeping in mind the needs of the students which ranged from basics of healthy eating patterns, study skills, writing skills, concentration and attention, career decision, relationship management, difficulties with learning, coping with stressors, resource management, concern about environmental issues to essential life skills like major event management, effective team building and group management, leadership training, crisis management. The activities were completely managed, planned and executed by the students who had opted Psychology as a one of their subjects for graduation degree in humanities. They were termed as Psycho Buddies and likewise categorized for the current study.

In the following study, the reader will find how these innovative \& experiential teaching-learning method has improved their satisfaction about life as a whole, efficiency for daily tasks, sociability factor, mental health and hygiene and interpersonal relations with people from varied age group. The activities were 
named as Life Buddies, Health and Hygiene Buddies, Study Buddies, Nutrition Buddies, Environment Buddies and so on.

\section{Interpersonal relations}

Normal adolescent development involves a gradual movement from interpersonal interactions with family to socializing with peers and friends. It is during this period, that they get an opportunity to learn to cope with psychological stress, deal with peer pressure, and develop self-confidence. These factors are essential for successful interpersonal relations with authority figures, peers or people younger to them [6].

\section{Sociability}

If understood in general terms, sociability refers to a preference of being in the company of self or others. It is understood to be based on the extent of preference for the number of social relationships [7].

\section{Life satisfaction}

Life satisfaction is defined as the way an individual evaluates his or her past or current conditions of life [89]. Life Satisfaction judgments refer to either global statements or describe a person's satisfaction with important domains of life, such as friends, family, or self [10]. With respect to youth, adolescents' global Life Satisfaction reports are strongly correlated with ratings of satisfaction with family, friends, school, living environment, and self [11]. It has been pointed out that life satisfaction is a key component for attainment of positive well-being in youth [12].

\section{Efficiency}

Efficiency if understood in line with the concept of self-efficacy as defined by Bandura [13] and is referred as one's belief in one's capability to organize and execute the courses of action required to achieve given results.

Psychological well-being is the subjective feelings of contentment, happiness satisfaction with life's experiences and one's role in the world of work, sense of achievement, utility belongingness, and no distress dissatisfaction or worry etc [14-15]. Researchers have shown that these factors affect adolescent's level of psychological well-being. The current study focuses exactly on these values and skills.

The importance of educating the students with these life skills has been stated by the World Health Organization for the development of following traits and achievement of the below mentioned goals in a student life: basic education; gender equality; democracy; good citizenship; child care and protection; quality and efficiency of the education system; the promotion of lifelong learning; quality of life; the promotion of peace.

It has been noted by Smith [16], that the most practical solution for universities with large number of students is to conduct lectures with the entire class together; which has been one of the reasons for student disengagement and lack of sustained attention to the subject matter taught by the instructor. Chrisotpher [17] also mentioned that the large classrooms and inattention and less interaction possibilities between student-teacher would lead to decreased attendance thereby hampering the student's academic performance and career decisions.

Research mentions how important it is to make sure that instructors meaningfully engage the students with constructive and creative tasks, and focus on expertise of content and delivery. It has long been identified that audio-visual teaching aids reinforce the spoken and written words in a classroom [18]. The current study also aims to strengthen this view by showing the impact of innovative \& experiential teachinglearning methods using images, animation, videos, presentations, graphical representations on improved understanding of the study material, permanence of the learnt subject, stimulates self-engagement and initiation toward studying.

Adolescence, often considered as the period of emotional development, is the crucial in building up appropriate emotion identification, and expression with least possible conflict with self and others. They do however, experience negative emotions in situation pertaining to career decisions, conceptual differences with parents or elders, differences of need and opinions among peers, dealing with academic 
pressure, and ideas about romantic relationships and arguments with such partners if any [19]. Researchers have mentioned that poor regulation of emotions make it difficult for adolescents to focus their attention, inability to solve problems and difficulty in relating to others [20]. An adolescent with effective regulation of emotions can pursue and prioritize different goals and mobilize these cognitions towards the achievement of life goals.

There is an increasing awareness among educators, mental health professionals and policy makers about youth mental health and well-being [21]. It is highly acknowledged that their health -physical and mental are indicators of increased positive social behaviour and less of risky behaviours. Literature on adolescent Life Satisfaction has clearly shown that it is made up of more than just one more outcome of various psychological states like positive affect and self- esteem. It is a strong indicator of physical health too [22]. It is noted by researchers that caring leaderships by the instructor leads to positive learning outcome, build solid relationships between students and teachers, and promotes self-engagement and pro-activeness by students by reducing negativity, disruptions, distractions and inattention [23]. Time and again it has been identified through researches that investing time and energy in building healthy relations with students result in productive and proactive behaviour by students [24].

The main objectives of the current study was to understand the mental health issues in undergraduate students, to find out the impact of teaching innovations on individual well-being of students and to study the impact of Psych buddies on Sociability \& Interpersonal relations of Undergraduate students.

The hypothesis was that there is significant difference between students exposed to teaching innovations (Psycho Buddies) and students not exposed to teaching innovations on Psychological Well-being.

\section{METHODOLOGY}

Independent variable: Teaching Innovation - Psycho Buddies and Non Psycho Buddies

Confounding variable: Gender - Male and Female

Dependent variable: Psychological Well-being

In the present study a total sample size of 136 students was considered, where in 21 male psycho buddies, 51 female psycho buddies, 34 male non psycho buddies and 30 female non psycho buddies were selected by stratified random sampling technique. The students were pursuing First Year, Second Year and Third Year Bachelor of Arts.

The students included in the studies had to be a part of 2016-17 Psycho buddies project initiated by M.D.College, age between 17-21 years and both genders.

The control group was not exposed to innovative teaching Psycho buddies project by M.D. College and had same age criteria as the study group.

\section{Scale Used}

The Psychological Wellbeing Scale (PWBS - SDCP) developed by Sisodia \& Choudhary [26] consists of 50 items with a five-point scale based on the lines of Likert having five alternatives to each items. Each item constitutes to one of the five given areas of psychological wellbeing. The five areas being measured are -

Area I: Life Satisfaction

Area II: Efficiency

Area III: Sociability

Area IV: Mental Health

Area V: Interpersonal relations

Reliability - The test-retest reliability of the scale was 0.87 and the consistency value was 0.90 .

Validity - The scale was validated against the external criteria and coefficient was 0.94 .

The selected sample was personally contacted and their consent was obtained to participate in this research study. They were briefed about the nature of the study. The standard instructions were given as per the manual of instructions. The data thus collected was analyzed. 


\section{STATISTICAL ANALYSIS}

The data was analysed as per the given norms and scoring instructions by applying descriptive statistics and one way analysis of variance to compare the psychological wellbeing. It was organized and classified according to the objective and hypothesis of the study. The scores were analyzed using SPSS to compute descriptive statistics and two way analysis of variance.

\section{RESULTS AND DISCUSSION}

Table 1 - Mean and standard deviation among Psycho buddies and non Psycho buddies on psychological wellbeing

\begin{tabular}{|lllllllll|}
\hline & \multicolumn{3}{l}{ Psycho buddies } & \multicolumn{4}{l|}{ Non Psycho Buddies } \\
& $\begin{array}{l}\text { Male } \\
\mathrm{n}=21\end{array}$ & & $\begin{array}{l}\text { Female } \\
\mathrm{n}=51\end{array}$ & & $\begin{array}{l}\text { Male } \\
\mathrm{n}=34\end{array}$ & & $\begin{array}{l}\text { Female } \\
\mathrm{n}=30\end{array}$ \\
\hline Mean & SD & Mean & SD & Mean & SD & Mean & SD \\
\hline $\begin{array}{l}\text { Life } \\
\text { Satisfaction }\end{array}$ & 36.92 & 4.22 & 37.00 & 4.846 & 36.09 & 3.972 & 36.57 & 2.725 \\
\hline Efficiency & 40.14 & 4.464 & 38.47 & 5.693 & 39.68 & 3.739 & 37.87 & 3.627 \\
\hline Sociability & 35.43 & 3.749 & 36.63 & 4.512 & 36.24 & 3.124 & 35.30 & 4.411 \\
\hline Mental Health & 35.95 & 5.10 & 33.33 & 5.06 & 35.18 & 3.88 & 33.23 & 3.97 \\
\hline $\begin{array}{l}\text { Interpersonal } \\
\text { Relations }\end{array}$ & 38.95 & 3.74 & 39.84 & 4.66 & 40.21 & 2.72 & 37.90 & 3.37 \\
\hline
\end{tabular}

Table 2 - Analysis of Variance

\begin{tabular}{|cccccc|}
\hline \multirow{2}{*}{ Area } & & $\begin{array}{c}\text { Sum of } \\
\text { Squares }\end{array}$ & df & Mean Square & F \\
\hline Life Satisfaction & Psycho-buddies & 3.062 & 1 & 3.06 & $.18^{\mathrm{NS}}$ \\
& Gender & 10.95 & 1 & 10.94 & $.64^{\mathrm{NS}}$ \\
& Intercept & .428 & 1 & .428 & $.025^{\mathrm{NS}}$ \\
\hline Efficiency & Psycho-buddies & 8.81 & 1 & .8 .81 & $.41^{\mathrm{NS}}$ \\
& Gender & 93.29 & 1 & 93.29 & $4.30^{\mathrm{NS}}$ \\
& Intercept & .15 & 1 & .15 & $.01^{\mathrm{NS}}$ \\
\hline Sociability & Psycho-buddies & 2.09 & 1 & 2.086 & $.13^{\mathrm{NS}}$ \\
& Gender & .535 & 1 & .535 & $.03^{\mathrm{NS}}$ \\
& Intercept & 35.04 & 1 & 35.04 & $2.12^{\mathrm{NS}}$ \\
\hline Mental Health & Psycho-buddies & 5.90 & 1 & 5.90 & $.28^{\mathrm{NS}}$ \\
& Gender & 160.14 & 1 & 160.14 & $7.67^{\mathrm{NS}}$ \\
& Intercept & 3.51 & 1 & 3.51 & $1.68^{\mathrm{NS}}$ \\
\hline Interpersonal & Psycho-buddies & 3.66 & 1 & 3.66 & $.25^{\mathrm{NS}}$ \\
Relations & Gender & 15.41 & 1 & 15.41 & $1.05^{\mathrm{NS}}$ \\
& Intercept & 78.62 & 1 & 78.62 & $5.36^{\mathrm{NS}}$ \\
\hline
\end{tabular}

No significant difference was noticed in life satisfaction of psycho buddies and non psycho buddies, which states that both psycho buddies and non psycho buddies displayed equal level of response of mind resulting from compliance with desires or demands. They also showed equivalent level of satisfaction, desire, contentment in enjoyment and gratification from life. 
No significant difference was noticed in efficiency of psycho buddies and non psycho buddies, which states that both psycho buddies and non psycho buddies reported equal ability of to perform or produce with consumption of resources. They showed equal quality of being efficient or producing effects, efficient power and effectual agency.

No significant difference was noticed in sociability of psycho buddies and non psycho buddies, thus indicating that psycho buddies and non psycho buddies show equal tendency to be sociable and associate with one's fellow.

No significant difference was noticed in mental health of psycho buddies and non psycho buddies stating that they are at equal level of cognitive and emotional wellbeing.

No significant difference was noticed in interpersonal relations of psycho buddies and non psycho buddies marking equal association by them with two or more people that may range from fleeting to enduring. This association may be based on love and liking, regular business interactions or some other type of social commitment.

\section{DISCUSSION}

The teachers and the students associated with Psycho Buddies, reported how the entire project has helped them develop confidence for interacting in the society, ability for public speaking, polish their talents for managing events and leading various teams for the project. They have mentioned how the activities have given them a chance to utilize their skills and efforts for the service of others in the community. These activities have shown the success of co-operative efforts, careful planning, efficient and productive task based efforts, dedication and responsibility in the given duties. The Psycho Buddies have reported the importance of planned behavior with appropriate goal-setting for academics as well as extra-curricular activities. Their examination marks card has shown tremendous increase in their performance and grades. They have reported increased attendance and adherence to regular college lectures. The students have preferred this particular college for their graduation majorly due to Psycho buddies, in spite of lengthy travel distance from their place of residence.

The limitations of the study are that most of the subjects came from rural background in their initial years, hence making it difficult to classify if the students are from rural or urban origin. Psychological wellbeing of the students before training was not assessed. For better results, assessment shall be done before and after the training.

This study was conducted only among college students. It can further be performed on various other age groups with different socio demographic dimensions. Study on rural, urban or semi urban population can be conducted separately in the future to consolidate the results obtained.

\section{CONCLUSIONS}

Based on the results and discussions, the following conclusions were drawn from the paper -

No significant difference was observed in psychological wellbeing like life satisfaction, efficiency, sociability, mental health and interpersonal relations among psycho buddies and non psycho buddies.

The test was administered in group. The respondents may have been influenced by responses of other group members. Language barrier for students having basics done in rural background was not eliminated and many negative sentences were difficult for many students to understand. The interaction of Psycho Buddies with non Psycho Buddies might have had an impact due to the peer discussions about the innovative ways of teaching.

\section{REFERENCES}

1. Campbell A. Subjective measures of well-being. Amer Psychol 1976;31(2):117-30.

2. Wells J, Barlow J, Stewart-Brown S. A systematic review of universal approaches to mental health promotion in schools. Health Educn 2003;103(4):197-220. 
3. Bastian VA, Burns NR, Nettelbeck T. Emotional intelligence predicts life skills, but not as well as personality and cognitive abilities. Personal Individ Diff 2005;39(6):1135-45.

4. Watkins ER. Constructive and unconstructive repetitive thought. Psychol Bull 2008;134(2):163-9.

5. Odle T. Emotional development. Education. com: An Aducation \& Child Development Site for ParentsParenting and Educational Resource. 2013.

6. Altman I, Taylor DA. Social penetration: The development of interpersonal relationships. Holt, Rinehart \& Winston; 1973.

7. Cohen S. Social relationships and health. Amer Psychol 2004;59(8):676-82.

8. Hahn EJ, Noland MP, Rayens MK, Christie DM. Efficacy of training and fidelity of implementation of the life skills training program. J School Health 2002;72(7):282-7.

9. Fogle LM, Huebner ES, Laughlin JE. The relationship between temperament and life satisfaction in early adolescence: Cognitive and behavioral mediation models. J Happiness Stud 2002;3(4):373-92.

10. Suldo SM, Thalji-Raitano A, Hasemeyer M, Gelley CD, Hoy B. Understanding Middle School Students Life Satisfaction: Does School Climate Matter?. Appl Res Qual Life 2013;8(2):169-82.

11. Suldo SM, Shaunessy-Dedrick E. The psychosocial functioning of high school students in academically rigorous programs. Psychol Schools 2013;50(8):823-43.

12. Suldo SM, Shaunessy-Dedrick E. Changes in stress and psychological adjustment during the transition to high school among freshmen in an accelerated curriculum. J Adv Acad 2013;24(3):195-218.

13. Bandura A. Social learning theory of aggression. J Communication 1978;28(3):12-29.

14. Shek DT, Wai CL. Training workers implementing adolescent prevention and positive youth development programs: what have we learned from the literature?. Adolescence 2008;43(172):823-9.

15. Lerner RM, Almerigi JB, Theokas C, Lerner JV. Positive youth development a view of the issues. J Early Adolesc 2005;25(1):10-6.

16. Tarrant M, North AC, Edridge MD, Kirk LE, Smith EA, Turner RE. Social identity in adolescence. J Adolescence 2001;24(5):597-609.

17. Gillham J, Adams-Deutsch Z, Werner J, Reivich K, Coulter-Heindl V, Linkins M, Winder B, Peterson C, Park N, Abenavoli R, Contero A. Character strengths predict subjective well-being during adolescence. J Positive Psychol 2011;6(1):31-44.

18. Baron J, Brown RV, editors. Teaching decision making to adolescents. Routledge; 2012.

19. Lerner RM, Steinberg L. Handbook of Adolescent Psychology, Volume 1: Individual Bases of Adolescent Development. John Wiley \& Sons; 2009.

20. Cole KA, Barker LR, Kolodner K, Williamson P, Wright SM, Kern DE. Faculty development in teaching skills: an intensive longitudinal model. Acad Med 2004;79(5):469-80.

21. Knopf HT, Swick KJ. Using our understanding of families to strengthen family involvement. Early Child Educn J 2008;35(5):419-27.

22. Gilman R, Meyers J, Perez L. Structured extracurricular activities among adolescents: Findings and implications for school psychologists. Psychol Schools 2004;41(1):31-41.

23. Muller $C$. The role of caring in the teacher-student relationship for at-risk students. Soc Inquiry 2001;71(2):241-55.

24. Botvin GJ, Griffin KW. Life skills training: Empirical findings and future directions. J Prim Prev 2004;25(2):211-32.

25. Komarraju M, Musulkin S, Bhattacharya G. Role of student-faculty interactions in developing college students' academic self-concept, motivation, and achievement. J College Stud Dev 2010;51(3):332-42.

26. McDowell I. Measures of self-perceived well-being. J Psychosom Res 2010;69(1):69-79.

$$
\begin{aligned}
& \text { Acknowledgements - Nil } \\
& \text { Source of Funding - Nil } \\
& \text { Conflict of Interest - Nil }
\end{aligned}
$$

